\title{
Compounds Exuded by Phaseolus vulgaris That Induce a Modification of Rhizobium etli Lipopolysaccharide
}

\author{
Dominik M. Duelli and K. Dale Noel \\ Department of Biology, Marquette University, Milwaukee, WI 53233, U.S.A. \\ Received 10 April 1997. Accepted 7 July 1997.
}

\begin{abstract}
Exudates released from germinating seeds and roots of a black-seeded bean (Phaseolus vulgaris cv. Midnight Black Turtle Soup) induce an antigenic change in the lipopolysaccharide (LPS) of Rhizobium etli CE3. By spectroscopic analyses and chromatographic comparisons with derived standards, the chemical structures of the aglycone portions of the major inducing molecules from seed exudate were deduced, and they were identified as delphinidin, cyanidin, petunidin, and malvidin. These anthocyanidins were present in seed exudate mainly as glycosides, the chief inducer being delphinidin 3-glucoside. Also present were 3-glucosides of petunidin and malvidin and glycosides of cyanidin and delphinidin. Seed exudate from a bean variety deficient in anthocyanins did not induce the LPS conversion. The ability of root exudate to induce an antigenic change in the LPS was due to compounds other than anthocyanins.
\end{abstract}

Additional keywords: flavonoid, rhizosphere, symbiosis.

Rhizobium etli and common bean interact to form root nodules in which the bacteria fix nitrogen. The success of this interaction is partly determined by preinfection events in the rhizosphere, mediated by signal molecules exchanged between the symbionts (Heidstra and Bisseling 1996; Schultze and Kondorosi 1996). In the best-characterized exchange of signals, host flavonoids activate bacterial nod genes (Peters et al. 1986; Hungria et al. 1991a,b), which direct the synthesis of specific lipooligosaccharides (Poupot et al. 1995). These lipooligosaccharide Nod factors in turn trigger early symbiotic events such as root-hair curling and root cortical cell division (van Rhijn and Vanderleyden 1995).

Host exudates also trigger other bacterial activities that may affect symbiotic proficiency (Hartwig et al. 1991; Aguilar et al. 1988; Kape et al. 1992). For instance, exudates induce changes in Rhizobium surface polysaccharides (Dunn et al. 1992; Reuhs et al. 1994, 1995; Noel et al. 1996). Although the symbiotic significance of these changes has not yet been established, Rhizobium mutants deficient in lipopolysaccharide (LPS) O-antigen or certain other polysaccharides are deficient in infection of their hosts (Noel 1992). The structural changes triggered by host compounds may facilitate the functions of these polysaccharides during the infection.

Corresponding author: K. Dale Noel; Telephone: 414-288-1475; Fax: 414-288-7357; E-mail: 6670NOELD@vms.csd.mu.edu
$R$. etli CE3 grown in the exudate released by germinating beans has a modified LPS that exhibits greatly decreased reaction with monoclonal antibody JIM28, in addition to other antigenic changes (Noel et al. 1996). This effect requires growth of the bacteria; it is not observed when exudate is incubated with isolated LPS. It does not require the $R$. etli Sym plasmid, the site of all known copies of nodD, the regulatory gene whose product activates nod gene expression. The major nod inducers of black bean seed exudate are anthocyanins (Hungria et al. 1991a). Inasmuch as induction of the LPS change does not require the key genetic regulator of nod induction, it was of interest to know whether the exudate compounds that induce the LPS change were different as well.

\section{RESULTS}

Release of active components from germinating seeds and preliminary fractionation.

Exudates sampled at different times during seed germination were assayed to determine their relative ability to trigger the LPS modification, hereinafter referred to as the inducing activity (IA). IA was measured by the decrease in relative binding of JIM28 antibodies to the LPS after growth of the bacteria in the presence of the sample being tested (Fig. 1). It was previously shown that the decrease in relative antibody binding is dependent on the concentration of the exudate (Noel et al. 1996). Antibody binding, therefore, was used as an inverse measure of the concentration of inducing compounds. These measurements showed that IA was strongest in what was exuded during the first $12 \mathrm{~h}$ of imbibition (Fig. 1A) and was highly correlated with the temporal profile of anthocyanin release from the seed (Fig. 1B).

To evaluate the chemical complexity of the inducers, solubility assessment and reverse-phase high-performance liquid chromatography (HPLC) were carried out. Active components partitioned preferentially into high-polarity solvents (Noel et al. 1996), and inducing activity was always associated with fractions having the most intense UV absorption and pigmentation, characteristics of classes of plant phenolics (Harborne 1973). Hence, crude exudate was analyzed by HPLC procedure A, developed for the separation of plant phenolics (Hungria et al. 1991a). HPLC yielded several consecutive fractions with activity (Fig. 2A); less than $25 \%$ of one of these fractions induced at least $60 \%$ conversion of the $R$. etli LPS to a form that did not bind JIM28 antibodies. All other fractions combined, even when concentrated from five HPLC runs, in- 
duced less than $20 \%$ antigenic conversion of the LPS in the IA assay, and all of these fractions combined had less activity than $3 \%$ of the combined fractions in the shaded portion of Figure $2 \mathrm{~A}$ and $\mathrm{B}$. The active fractions had absorption maxima between 530 and $560 \mathrm{~nm}$ (Fig. 2B), which is a characteristic of anthocyanins. Active fractions of root exudate (Fig. 2C) differed from active fractions of seed exudate in absorption and elution characteristics and are discussed later.

\section{Isolation and characterization of compounds with IA.}

To determine whether anthocyanins accounted for the IA of the active fractions, material from the active fractions and material exuded during the first $12 \mathrm{~h}$ of germination was separated by HPLC procedure B, optimized for resolving different anthocyanins (anthocyanidin glycosides) (Fig. 3A). IA was associated exclusively with five HPLC fractions (peaks 1.1gly4gly in Fig. 3A) when assayed by the same criteria described above. The combined activity of these fractions accounted for

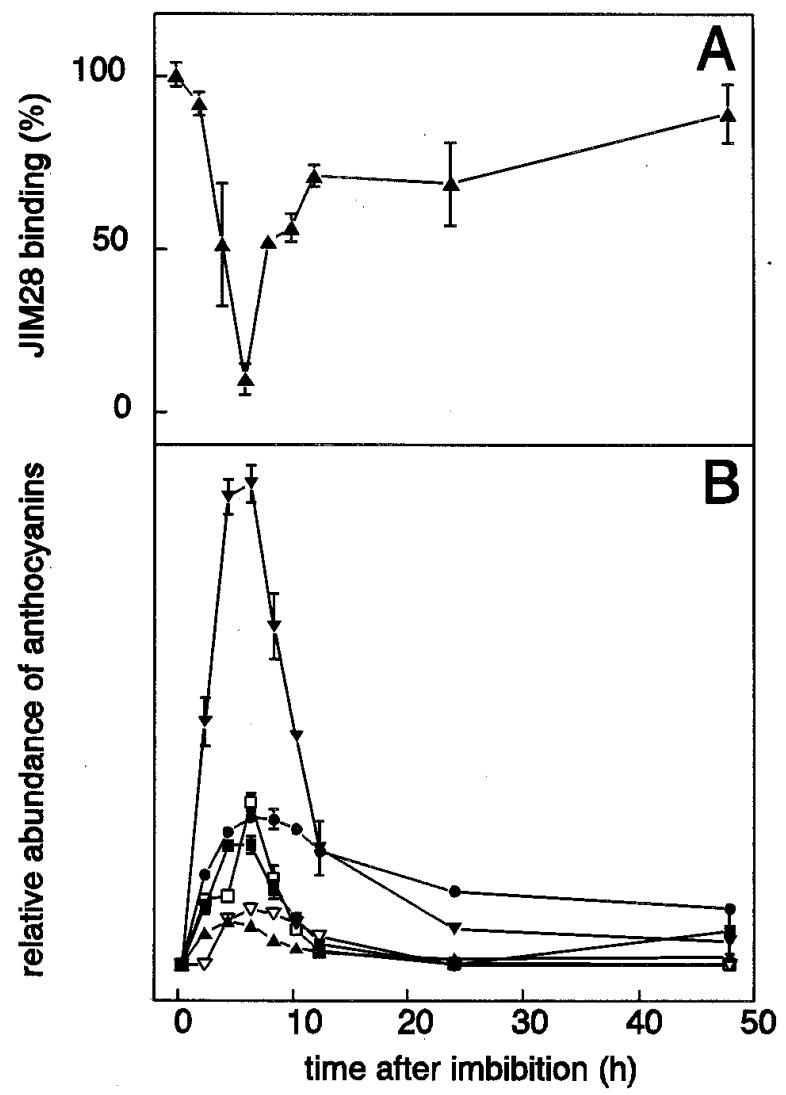

Fig. 1. A, Inducing activity (IA) in the exudate of germinating seeds, measured by the decrease in relative binding of monoclonal antibody JIM28 to lipopolysaccharide (LPS) of Rhizobium etli (an inverse function of IA). The values are the means of three replicate samples of exudate released by germinating beans at each time point, normalized according to the number of the beans and the number of bacteria treated. B, Release of anthocyanins from germinating seeds. Values represent typical release of anthocyanin during germination. Anthocyanins contained in crude exudate were separated by thin-layer chromatography, and the optical density of individual anthocyanin bands in the chromatogram was quantitated: $\boldsymbol{\nabla}$, delphinidin 3-glucoside; $\boldsymbol{O}$, petunidin 3-glucoside; $\mathbf{\square}$, malvidin 3-glucoside; $\square$, cyanidin glycoside; $\nabla$, delphinidin glycoside.
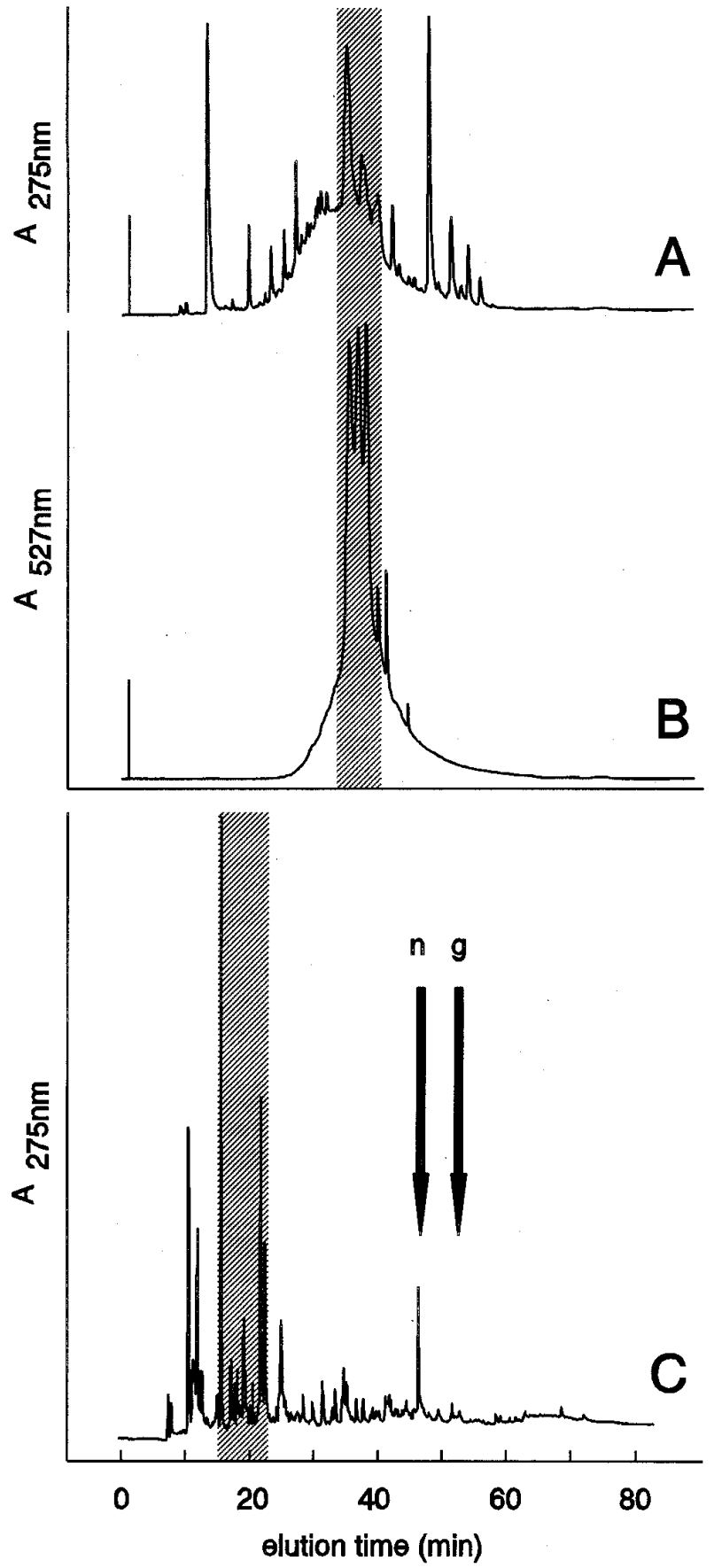

Fig. 2. High-performance liquid chromatography (HPLC) profiles of exudates from seeds and young roots. $\mathbf{A}$ and $\mathbf{B}$, A sample corresponding to the exudate released by five seeds during the first $12 \mathrm{~h}$ of imbibition was fractionated according to HPLC procedure A and monitored for eluate absorption at 275 and $527 \mathrm{~nm}$, respectively. C, Root exudate from 10 seedlings collected $72-96 \mathrm{~h}$ after the start of imbibition was subjected to the same conditions as the seed exudate. The arrows indicate the elution times of naringenin $(\mathrm{n})$ and genistein $(\mathrm{g})$. The shaded portions indicate fractions with detectable inducing activity (IA). The other fractions had less than $5 \%$ of the IA exhibited by the least active of the shaded fractions. 
approximately $90 \%$ of the activity of crude seed exudate. Each of these fractions contained anthocyanins, as they had absorption maxima between 530 and $560 \mathrm{~nm}$ (Table 1). To determine the anthocyanidin portion (anthocyanidin aglycone) of the anthocyanins contained in these fractions, compounds of the individual fractions were acid-hydrolyzed, and the identity of the derived anthocyanidin aglycones and the released sugars was determined by standard assays (Strack and Wray 1989; York et al. 1985).

Acid hydrolysis of compounds associated with each peak, followed by extraction in ethyl acetate and amyl alcohol and separation by HPLC procedure C, optimized for resolving different anthocyanidin aglycones, yielded a total of four separate anthocyanidins (peaks $1 \mathrm{a}-4 \mathrm{a}$ in Fig. 3B). Each anthocyanin peak yielded no more than one anthocyanidin. Hydrolysis of compounds in peaks $1.1 \mathrm{gly}$ and $1.2 \mathrm{gly}$ yielded peak 1a; the contents of $2 \mathrm{gly}, 3 \mathrm{gly}$, and 4 gly yielded peaks $2 \mathrm{a}$, $3 \mathrm{a}$, and $4 \mathrm{a}$, respectively (Table 1 ). Analysis of compounds purified from peaks 1a through 4a produced data consistent with the published characteristics of the anthocyanidins delphinidin

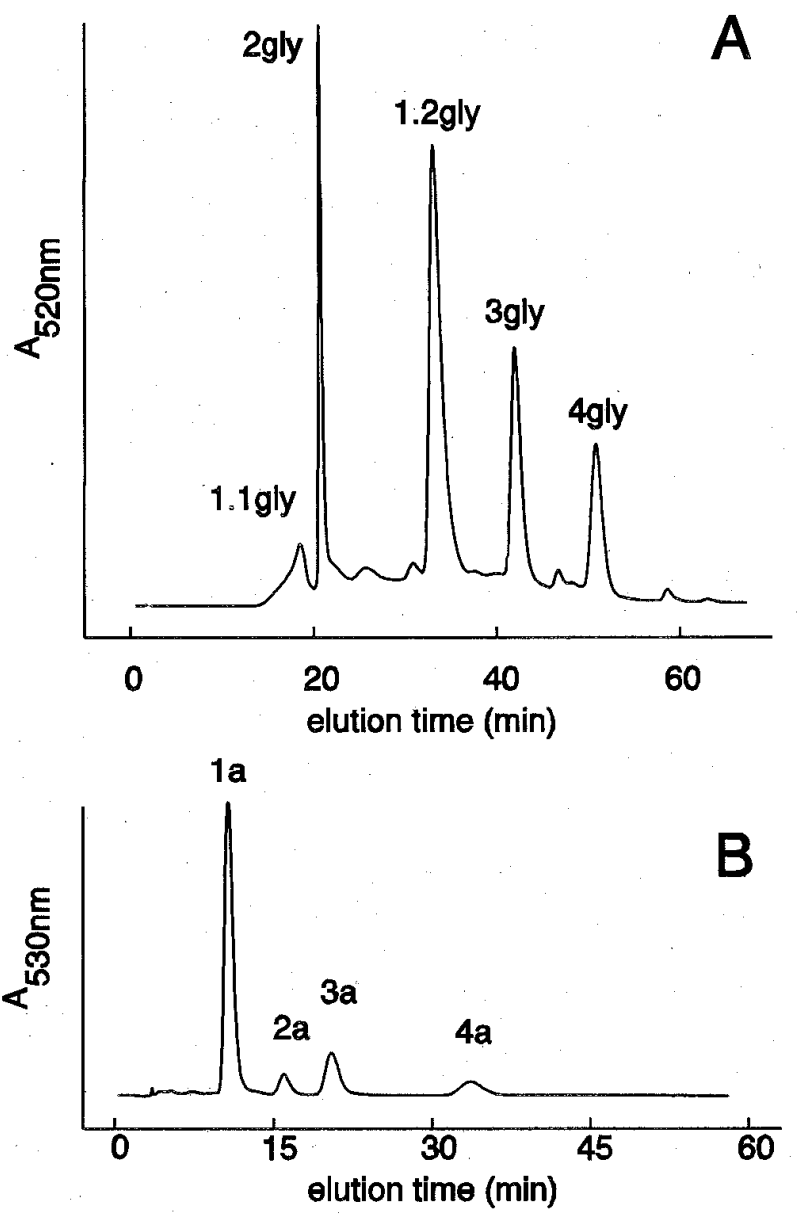

Fig. 3. High-performance liquid chromatography (HPLC) profiles of seed exudate released during the first $12 \mathrm{~h}$ of imbibition. A, Unhydrolyzed exudate from five seeds fractionated by HPLC method B for anthocyanidin glycosides and monitored for eluate absorption at $520 \mathrm{~nm}$. B, Acid-hydrolyzed exudate from five seeds fractionated by HPLC method $\mathrm{C}$ for anthocyanidins and monitored for eluate absorption at 530 nm. $\left(3,5,7,3^{\prime}, 4^{\prime}, 5^{\prime}\right.$-hexahydroxyflavylium), cyanidin $\left(3,5,7,3^{\prime}, 4^{\prime}-\right.$ pentahydroxyflavylium), petunidin $\left(3,5,7,4^{\prime}, 5^{\prime}\right.$-pentahydroxy$3^{\prime}$-methoxyflavylium), and malvidin (3,5,7, $4^{\prime}$-tetrahydroxy$3^{\prime}, 5^{\prime}$-dimethoxyflavylium), respectively (Fig. 4 and Table 2).

These assignments were based on the following data. (i) Maximum absorption of UV and visible light $\left(\mathrm{UV}_{\max }\right.$ and $\mathrm{vis}_{\text {max }}$ ) (Table 1) matched published data for delphinidin (1a), cyanidin (2a), petunidin (3a), and malvidin (4a). (ii) The UV and visible absorption spectra matched the spectra obtained in this study from a commercial sample of delphinidin (1a), cyanidin purified from raspberries (2a), and malvidin purified from Concord grapes (4a). (iii) Bathochromic shifts of the visible spectrum peak in the presence of aluminum ion (Table 1 ) indicated $O$-dihydroxyl groups in the B-ring (Fig. 4) for delphinidin (1a), cyanidin (2a), and petunidin (3a), but not malvidin (4a) (Harborne 1967) (Table 1). (iv) Chromatography of the anthocyanidins of peaks 1a, 2a, and 4a by HPLC procedure C, thin-layer chromatography (TLC), and gas chromatography (GC) matched that of commercial delphinidin, derived cyanidin, and malvidin, respectively. No standard was available for comparison with the anthocyanidin of peak $3 \mathrm{a}$, but its retention time on HPLC and GC relative to cyanidin, malvidin, and pelargonidin is consistent with its being petunidin (Wilkinson et al. 1977). (v) High-resolution fast atom bombardment mass spectra showed the $\mathrm{m} / \mathrm{z}$ of an $\left(\mathrm{M}+\mathrm{H}^{+}\right)$of 303.0504 for the content of peak 1a, which corresponds to the chemical composition $\mathrm{C}_{15} \mathrm{H}_{11} \mathrm{O}_{7}$, consistent with delphinidin, and the fragmentation pattern of the commercial delphinidin.

The anthocyanins in peaks $1.2 \mathrm{gly}, 3 \mathrm{gly}$, and $4 \mathrm{gly}$ carried a sugar residue at $\mathrm{C} 3$, as deduced from the following data. (i) The vis ${ }_{\max }$ of the anthocyanins in peaks $1.2 \mathrm{gly}, 3 \mathrm{gly}$, and $4 \mathrm{gly}$ was at a lower wavelength than measured for their anthocyanidin aglycones (Table 1), which is a characteristic of 3glycosylation (Harborne 1967). (ii) $\mathrm{UV}_{\max }$ and vis ${ }_{\max }$ absorption (Table 1) matched published data for delphinidin 3-glycoside (1.2gly), petunidin 3-glycoside (3gly), and malvidin 3-glycoside (4gly) (Harborne 1967) (Table 1). Anthocyanins in $1.2 \mathrm{gly}, 3 \mathrm{gly}$, and $4 \mathrm{gly}$ were not glycosylated at C5, as (i) the $\mathrm{A}_{440} / \mathrm{A}_{\text {vis max }}$ ratio was 0.17 to 0.21 , whereas a ratio of 0.13 or less indicates diglycosylation (Harborne 1967), and (ii) the $\mathrm{A}_{\mathrm{UV} \max } / \mathrm{A}_{\mathrm{vis} \max }$ ratio was 0.59 to 0.66 , whereas a ratio of 0.44 or less indicates diglycosylation (Harborne 1967).

On the basis of the following data, it was deduced that the

Table 1. Absorption of UV and visible light and sugar moieties of the contents of high-performance liquid chromatography (HPLC) peaks

\begin{tabular}{|c|c|c|c|c|c|}
\hline \multirow[b]{2}{*}{$\begin{array}{l}\text { HPLC } \\
\text { peak }^{\text {a }}\end{array}$} & \multirow[b]{2}{*}{ Color } & \multicolumn{2}{|c|}{ Absorption (nm) } & \multirow[b]{2}{*}{$\begin{array}{c}\mathrm{AlCl}_{3} \\
\text { shift }\end{array}$} & \multirow[b]{2}{*}{ Sugar content $^{\mathbf{b}}$} \\
\hline & & UV & $\begin{array}{c}\text { Visible } \\
\text { light }\end{array}$ & & \\
\hline $1 \mathrm{a}$ & Purple & 276 & 548 & + & \\
\hline $1.1 \mathrm{gly}$ & Purple & 272 & 534 & + & Glucose, galactose \\
\hline $1.2 \mathrm{gly}$ & Purple & 275 & 534 & + & Glucose \\
\hline $2 \mathrm{a}$ & Magenta & 278 & 538 & + & \\
\hline 2gly & Magenta & 272 & 522 & + & Glucose, galactose \\
\hline $3 a$ & Purple red & 277 & 545 & + & \\
\hline 3gly & Purple & 276 & 535 & + & Glucose \\
\hline $4 a$ & Purple red & 276 & 544 & 0 & \\
\hline $4 \mathrm{~g}$ & Purple & 275 & 535 & 0 & Glucose \\
\hline
\end{tabular}

${ }^{a}$ HPLC peaks are described in Figure 3.

${ }^{\mathrm{b}}$ Sugars were identified by gas chromatography after trimethylsilyl derivation. 
anthocyanins in peaks $1.2 \mathrm{gly}, 3 \mathrm{gly}$, and 4 gly are glucosides. (i) The sugars of $1.2 \mathrm{gly}, 3 \mathrm{gly}$, and $4 \mathrm{gly}$ were identified as glucose by GC of trimethylsilyl (TMS) derivation of the sugars released in the acid hydrolysates. (ii) Peaks 1.2gly, 3gly, and 4 gly eluted in accordance with previously established chromatographic properties for delphinidin 3-glucoside, petunidin 3-glucoside, and malvidin 3-glucoside in HPLC procedure B (Williams et al. 1978) (Fig. 3A).

The delphinidin glycoside of peak 1.1 gly and the cyanidin glycoside of peak 2 gly contain at least two glycosidic groups, as deduced from the release of TMS-derived glucose and galactose upon acid hydrolysis. The 3,5-glycosylation of these anthocyanidins is suggested by HPLC chromatographic behavior (Williams et al. 1978); $\mathrm{UV}_{\max }$ and vis ${ }_{\max }$ absorption (Table 1); and $\mathrm{A}_{\mathrm{UV} \max } / \mathrm{A}_{\mathrm{vis} \max }$ ratios of 0.40 and 0.42 and $\mathrm{A}_{440} / \mathrm{A}_{\text {vis max }}$ ratios of 0.10 and 0.12 , matching published data for delphinidin 3,5-diglycoside (1.1gly) and cyanidin 3,5diglycoside (2gly), respectively (Harborne 1967). None of the anthocyanins had absorption peaks characteristic of acyl groups (Harborne 1967), as $\mathrm{A}_{310-335} / \mathrm{A}_{\text {vis max }}$ ratios less than 0.2 were recorded for each anthocyanin.

\section{Abundance and activity of individual inducers.}

As no molar extinction coefficients were available for the anthocyanidin diglycosides in seed exudate, quantities of anthocyanins in seed exudate were determined by taking advantage of the published molar extinction coefficients for anthocyanidins, as follows. First, anthocyanidin recovery during isolation was assessed by supplementing exudate from germinating seeds with pelargonidin glycoside (pelargonin). Approximately $68 \%$ of the anthocyanidin portion of supplemented pelargonin was recovered after acid hydrolysis and subsequent separation of individual anthocyanidins (HPLC procedure $\mathrm{C}$ ). Corrected for this loss during isolation, the quantities of individual anthocyanidins released per germinated seed during the first $12 \mathrm{~h}$ ranged from $44 \mathrm{nmol}$ of malvidin to $207 \mathrm{nmol}$ of delphinidin (Table 2). The yield of anthocyanidins released by hydrolysis of exudate collected during $12 \mathrm{~h}$ of imbibition corresponded to $58 \%$ of the amount of anthocyanidins recovered by acid extraction of ungerminated beans.

To compare the IA of individual purified anthocyanidin aglycones (Fig. 5A), the concentration of anthocyanidin required to effect a $50 \%$ induction of the LPS modification $\left(\mathrm{I}_{50}\right)$ was assessed. The $\mathrm{I}_{50}$ for anthocyanidin 3-glycosides was 40 to $50 \mu \mathrm{M}$, whereas the $\mathrm{I}_{50}$ of the anthocyanidin aglycones was generally lower (Fig. 5B). Of the aglycones, delphinidin had the lowest $\mathrm{I}_{50}(8 \mu \mathrm{M})$, and malvidin the highest $(40 \mu \mathrm{M})$. At concentrations exceeding $100 \mu \mathrm{M}$, aglycones were severely growth-inhibitory to $R$. etli CE3, as indicated by the intensities of silver-stained LPS from a given culture volume, whereas the glycosides were not significantly inhibitory to growth at concentrations up to $600 \mu \mathrm{M}$. Pelargonidin, an anthocyanidin not found in Phaseolus vulgaris cv. Midnight Black Turtle Soup was also an efficient inducer, with $\mathrm{I}_{50}<15 \mu \mathrm{M}$.

\section{IA of root exudate.}

Four consecutive HPLC fractions from root exudate had IA (Fig. 2C). Compounds in these HPLC fractions had no absorption above $305 \mathrm{~nm}$ and UV spectra reminiscent of simple phenolics (Harborne 1973). These compounds eluted earlier than the major nod inducers of root exudate, naringenin and genistein (Fig. 2C). When tested as pure compounds, genistein had no IA at concentrations of $1.2 \mathrm{mM}$ or less, whereas naringenin was a weak inducer, with $\mathrm{I}_{50}>1 \mathrm{mM}$. At this concentration, naringenin strongly inhibited growth. HPLC fractions having the major root IA displayed no apparent growth inhibition at concentrations 50 times higher than those needed for full antigenic conversion of the LPS. The four HPLC fractions from root exudate with IA also eluted earlier than the anthocyanins from seed exudate during co-chromatography (Fig. 2B and C).

\section{Activity of exudates from white-seeded $\boldsymbol{P}$. vulgaris.}

To substantiate the conclusion that the IA of seed exudate was due to anthocyanins, a commercial variety of $P$. vulgaris expected to be deficient in anthocyanins was tested (Dickson and Petzoldt 1988). The concentrated exudate of Navy bean

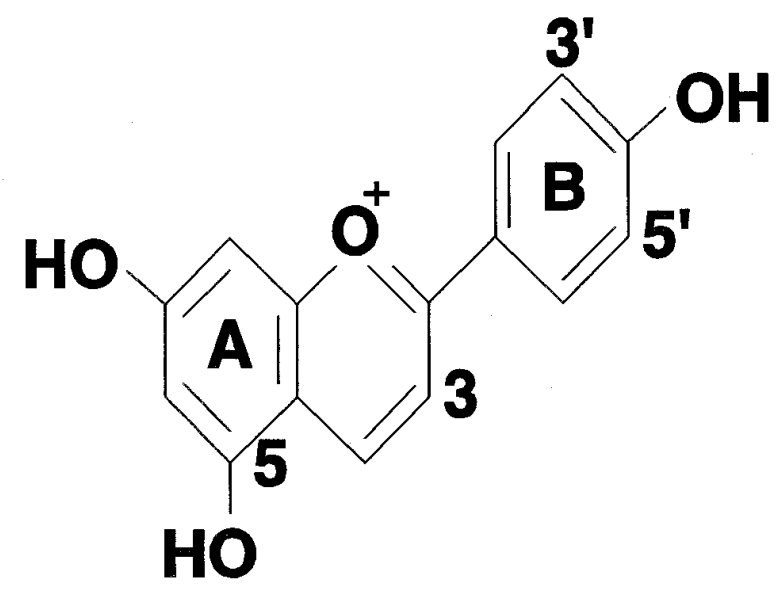

Fig. 4. Common structure of anthocyanins of seed exudate. Specific variations are given in Table 2.

Table 2. Structures and abundance of isolated inducers

\begin{tabular}{|c|c|c|c|c|c|c|}
\hline \multirow[b]{2}{*}{ HPLC peak } & \multicolumn{5}{|c|}{ Substituent $^{\mathrm{a}}$} & \multirow{2}{*}{$\begin{array}{c}\text { Abundance } \\
(\text { nmol })\end{array}$} \\
\hline & C5 & $\mathbf{C 3}$ & $\mathbf{C 3}^{\prime}$ & $\mathbf{C 5}^{\prime}$ & Aglycone & \\
\hline $1.1 \mathrm{gly}$ & -O-glycoside & -O-glycoside & $-\mathrm{OH}$ & $-\mathrm{OH}$ & Delphinidin & $7^{\mathrm{c}}$ \\
\hline $1.2 \mathrm{gly}$ & $-\mathrm{OH}$ & -O-glucoside & $-\mathrm{OH}$ & $-\mathrm{OH}$ & Delphinidin & $200^{\mathrm{c}}$ \\
\hline 2 gly & -O-glycoside & -O-glycoside & $-\mathrm{OH}$ & $-\mathrm{H}$ & Cyanidin & 53 \\
\hline 3gly & $-\mathrm{OH}$ & - $O$-glucoside & $-\mathrm{OMe}$ & $-\mathrm{OH}$ & Petunidin & 77 \\
\hline 4gly & $-\mathrm{OH}$ & -O-glucoside & $-\mathrm{OMe}$ & $-\mathrm{OMe}$ & Malvidin & 44 \\
\hline
\end{tabular}

${ }^{a}$ The positions of the attachments are shown in Figure 4.

${ }^{\mathrm{b}}$ Anthocyanin released per germinating seed during the first $12 \mathrm{~h}$ of germination.

${ }^{\mathrm{c}}$ Based on relative areas of $1.1 \mathrm{gly}$ and $1.2 \mathrm{gly}$ from high-performance liquid chromatography (Fig. 3A). 
C-20 had no detectable anthocyanin and no detectable IA. At the concentrations tested, and with the resolution of the assay, this cultivar had less than $1 \%$ of the IA and less than $0.1 \%$ of the anthocyanin found in samples of the the same weight of cultivar Midnight Black Turtle Soup. Root exudate from Navy bean C-20 exhibited activity comparable to that of black beans. Furthermore, the root compounds of Navy bean C-20 having IA eluted similarly to active root compounds of black beans.

\section{DISCUSSION}

The LPS modification of $R$. etli CE3 in response to seed exudate of $P$. vulgaris can be attributed mainly to anthocyanins. Significant IA after HPLC of crude exudate was found only in fractions containing anthocyanins (i.e., fractions in the shaded portion of Fig. 2A and B). As another measure, the combined activity of the anthocyanins purified from seed exudate would account for approximately $90 \%$ of the total ac-

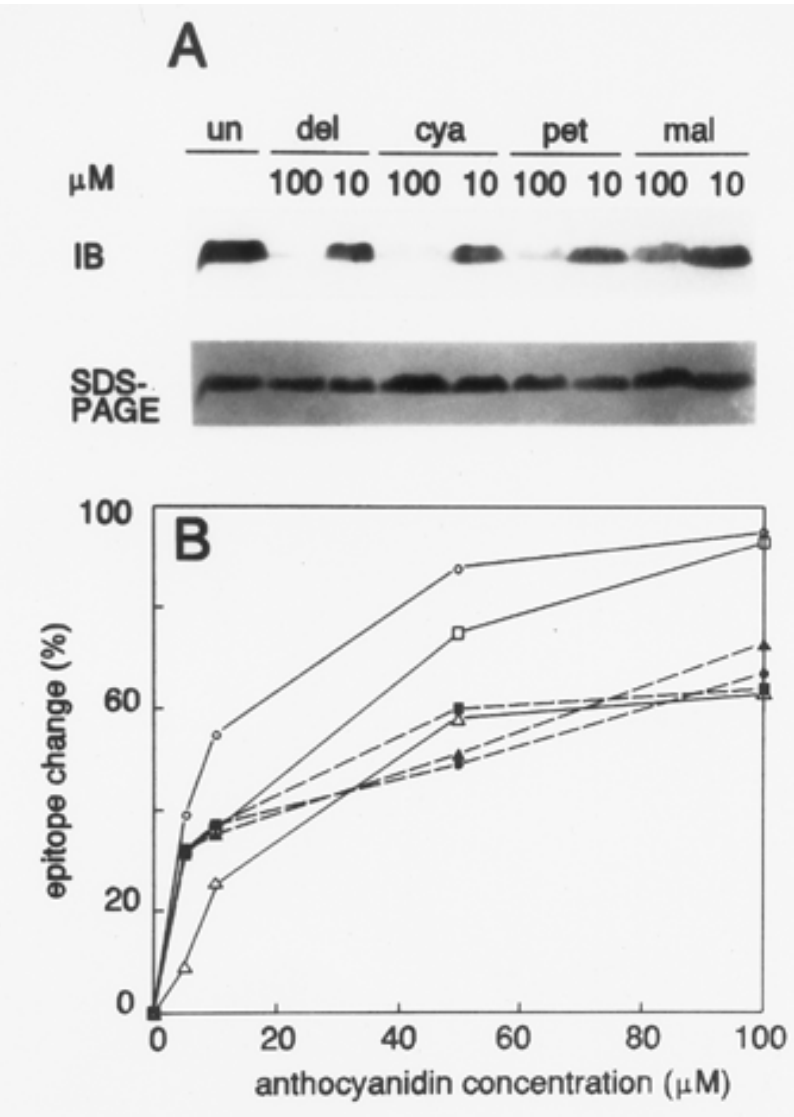

Fig. 5. A, Typical bioassay for induction of the modification of lipopolysaccharide (LPS) by anthocyanidin aglycones. LPS I of Rhizobium etli grown in the absence of anythocyanidins (un) or in the presence of delphinidin (del), cyanidin (cya), petunidin (pet), or malvidin (mal) was separated by sodium dodecyl sulfate-polyacrylamide gel electrophoresis, blotted onto nitrocellulose, and probed with monoclonal antibody JIM28 (IB). Residual LPS in the gel was silver-stained (SDS-PAGE). In each bioassay, LPS was extracted from cells grown in the presence of either 100 or $10 \mu \mathrm{M}$ anthocyanidins. B, Comparative induction by aglycones (open symbols) and glycosides (closed symbols) of anthocyanidins (averages of two replicates): $\mathrm{O}$, delphinidin; $\bullet$, delphinidin 3-glucoside; $\square$, petunidin; $\boldsymbol{\square}$, petunidin 3-glucoside; $\Delta$, malvidin; $\boldsymbol{\Lambda}$, malvidin 3-glucoside. tivity measured in crude seed exudate. Moreover, seed exudate from Navy bean C-20, which lacks anthocyanins, also lacks IA. Conversely, the seed exudate of all colored varieties of bean that have been tested induce the LPS change (Noel et al. 1996), and the color of bean seed coats is generally due to anthocyanins (Yoshida et al. 1996).

The major anthocyanins of cultivar Midnight Black Turtle Soup were the glycosides of delphinidin, cyanidin, petunidin, and malvidin. The presence of similar anthocyanins in blackseeded common bean was previously reported (Hungria et al. 1991a; Mazza and Miniati 1993; Yoshida et al. 1996). Delphinidin 3-glucoside was the major inducer produced by this cultivar in this study, being the most abundant (Table 2) and having the strongest IA (Fig. 5).

Although the anthocyanins in bean seed exudate induce both the nod genes (Hungria et al. 1991a) and this LPS antigenic change, there are several differences between nod induction and this LPS modification. The Sym plasmid is required for nod induction in $R$. etli but not for exudate-induced LPS modification (Noel et al. 1996), suggesting that the LPS modification is induced independently of NodD, the key regulatory protein for nod induction. Furthermore, naringenin and genistein are strong nod inducers but extremely poor effectors of the LPS change. There are also differences between nod induction and IA in regard to the effects of anthocyanidin substituents. Decreased methoxylation (Table 2) and lack of glucosylation (Fig. 5) appear to promote greater induction of the LPS modification, whereas glycosylation and increased methoxylation of anthocyanidins results in greater nod transcription (Hungria et al. 1991a). Also, the published $\mathrm{I}_{50}$ of nod induction (Hungria et al. 1991a) is at least 10 times smaller than the $I_{50}$ of the LPS change (Fig. 5). However, this difference must be interpreted with caution; nod induction has been measured in shorter-term assays of lac-fused gene activation, whereas the present assay of the LPS change requires a long period of growth.

In this study, delphinidin glycosides were released by exudation from seed at approximately $200 \mathrm{nmol}$ per seed in $12 \mathrm{~h}$, and in a previous study they were released in even greater abundance from other cultivars (Hungria et al. 1991a). If this quantity were distributed equally throughout a $2-\mathrm{cm}^{3}$ sphere surrounding the germinating seed, the resulting concentration of $100 \mu \mathrm{M}$ delphinidin glycosides alone would be sufficient to trigger the conversion of more than $50 \%$ of the LPS of $1 \times 10^{9}$ $R$. etli (Fig. 5B). The actual concentrations encountered by $R$. etli in the soil are complicated by adsorption effects and degradation. Nevertheless, because of restricted diffusion, it is not unreasonable that effective concentrations near germinated seedlings are even higher than the $100 \mu \mathrm{M}$ calculated above. Hence, the $\mathrm{I}_{50}$ values determined in vitro are at least consistent with a physiologically relevant role.

Efforts are currently under way to assess the significance of this LPS change in $R$. etli by isolating and studying mutants that are no longer able to modify the LPS in response to seed exudate. It was previously reported that a mutant (CE374) with reduced proficiency in changing the epitope also exhibits symbiotic defects, whereas a mutant (CE367) that constitutively lacks the JIM28 epitope shows no symbiotic deficiencies, indicating that modification of the JIM28 epitope may facilitate symbiosis (Tao et al. 1992; Noel et al. 1996). More recently isolated mutants that do not change their epitope in 
response to seed exudate, in addition to having a truncated LPS, have severe symbiotic deficiencies (D. M. Duelli, V. J. Neuman, and K. D. Noel, unpublished data).

Host compounds have been shown to affect the synthesis or processing of at least four types of rhizobial polysaccharides (Reuhs et al. 1994, 1995; Dunn et al. 1992; Dazzo et al. 1982). Isoflavonoids were the inducers tested by Reuhs et al. (1994) and Dunn et al. (1992), but they do not appear to be effective in triggering the LPS change in $R$. etli. It may be that such host-induced modifications of Rhizobium polysaccharides are widespread and important in the symbiosis. It would be interesting to know whether these other host-induced polysaccharide changes resemble the $R$. etli LPS change in not requiring the Sym plasmid.

\section{MATERIALS AND METHODS}

\section{Bacterial strains and growth conditions.}

Strain CE3 is a streptomycin-resistant, symbiotically proficient derivative of wild isolate $R$. etli CFN42 (Noel et al. 1984; Segovia et al. 1993). Bacterial cultures were grown at $30^{\circ} \mathrm{C}$ in various types of tubes in a rotating shaker at $150 \mathrm{rpm}$ in $\mathrm{TY}$ liquid medium, containing tryptone, yeast extract, and $\mathrm{CaCl}_{2}$ (VandenBosch et al. 1985). TY liquid medium was titrated to $\mathrm{pH} 6.0$, because that was found to be the optimal $\mathrm{pH}$ for induction of the LPS change by seed exudate. Control experiments showed that another LPS change, which is induced by $\mathrm{pH}$ values below 5.5 (Tao et al. 1992), was not triggered at pH 6.0.

\section{Monoclonal antibodies.}

Monoclonal antibody JIM28, as described by Tao et al. (1992), was a generous gift from N. J. Brewin (Norwich, UK).

\section{Assay of activity that induces the LPS modification (IA).}

For tests of the effects of exudate, $2 \times 10^{7}$ bacteria were grown in TY liquid containing a given HPLC fraction, exudate aliquot, or standard anthocyanin and shaken at $30^{\circ} \mathrm{C}$ for $24 \mathrm{~h}$ at an initial $\mathrm{pH}$ of 6.0. Pelleted and washed bacterial cells from these cultures were extracted in sodium dodecyl sulfate (SDS) buffer at $100^{\circ} \mathrm{C}$. After centrifugation to remove insoluble debris, the extracts were subjected to SDS-polyacrylamide gel electrophoresis (SDS-PAGE) on a BioRad Mini-Protean II electrophoresis system according to the manufacturer's instructions. LPS remaining in the resolving gel after electroblotting onto nitrocellulose was stained with a periodate-silver treatment, and nitrocellulose blots were probed with antibody JIM28. Details of this procedure and the quantitation of relative reactivity with JIM28 (an inverse measure of IA) were previously described (Noel et al. 1996). For quantitation of IA, gel lanes were loaded to give roughly equal amounts of LPS.

\section{Collection of seed exudate.}

Exudate was collected from $P$. vulgaris cv. Midnight Black Turtle Soup (Johnny's Selected Seeds, Albion, ME, and AgriSales, Twin Falls, ID), tested for microbial contamination, and filter-sterilized by procedure B of Noel et al. (1996).

\section{Assessment of chemical complexity of inducers by HPLC (HPLC procedure A).}

Preliminary isolation of compounds from seed exudate with IA was performed by modified procedures of Hungria et al. (1991a): The lyophilized crude sample was resuspended in water and adsorbed to a 900-mg $\mathrm{C}_{18}$ Maxi-Clean cartridge (Alltech Associates, Deerfield, IL). This preparation, from a sample corresponding to the exudate released by five beans, was reconstituted in 50\% methanol and injected into an ISCO model 2350 HPLC system equipped with a Maxsil $\mathrm{C}_{18}$ guard column $(50 \times 10 \mathrm{~mm}$, particle size $5 \mu \mathrm{m})$ and a Maxsil $\mathrm{C}_{18}$ semipreparative reverse-phase column $(250 \times 10 \mathrm{~mm}$, particle size $5 \mu \mathrm{m}$ ) (Phenomex). The column was eluted at $2.0 \mathrm{ml} \mathrm{min}^{-1}$ with methanol-water-acetic acid in a 90-min linear gradient from 0:99:1 to 99:0:1 (v/v). Compounds were monitored with a Linear UVIS 201 detector that measured absorption (at 550 $\mathrm{nm}$ ) every second. Eluent fractions were collected every minute, dried under vacuum, redissolved in $2 \%$ methanol, titrated to $\mathrm{pH}$ 6.0, and tested for IA.

\section{Isolation of anthocyanidin glycosides from seed exudate (HPLC procedure B).}

Pooled and dried eluent fractions of the initial HPLC separation having IA and also crude seed exudate from a sample corresponding to five beans (Noel et al. 1996) were redissolved in $1 \%$ acetic acid and separated on a $\mu$ BondPack analytical reverse-phase column $(3.9 \times 300 \mathrm{~mm})$ (Waters). The column was eluted at $0.2 \mathrm{ml} \mathrm{min}^{-1}$ for $40 \mathrm{~min}$ with wateracetic acid-methanol in a convex-curved gradient from $84: 15: 1$ to $65: 15: 20$ (curve 8 of the ISCO ChemResearch 150 Chromatographic System Controller), followed by isocratic elution with water-acetic acid-methanol (65:15:20) for 10 $\mathrm{min}$ at $0.2 \mathrm{ml} \mathrm{min}^{-1}$ and then $10 \mathrm{~min}$ at $0.3 \mathrm{ml} \mathrm{min}^{-1}$, according to Williams et al. (1978). Absorption at $520 \mathrm{~nm}$ was measured every second. A sample of each peak was repurified under the same HPLC conditions before IA quantitation and derivation to anthocyanidin aglycones as outlined below.

\section{Isolation of anthocyanidin aglycones from seed exudate (HPLC procedure C).}

Preparation of anthocyanidin aglycones from exudate, HPLC fractions, purified anthocyanidin glycosides, and ungerminated seeds was carried out as outlined by Harborne (1973). Pooled and dried eluent fractions with IA and crude exudate from a sample corresponding to five beans were hydrolyzed in $1.0 \mathrm{ml}$ of $2 \mathrm{~N} \mathrm{HCl}$ for $40 \mathrm{~min}$ at $100^{\circ} \mathrm{C}$. Ungerminated seeds were hydrolyzed in an equal volume $(w / v)$ of $4 \mathrm{~N} \mathrm{HCl}$ for 40 $\min$ at $100^{\circ} \mathrm{C}$. The decanted and filtered seed extract and the exudate hydrolysates were extracted with ethyl acetate to remove other flavonoids. The resulting aqueous fraction was extracted with amyl alcohol to enrich for anthocyanidins. The amyl alcohol fraction was dried in vacuo, redissolved in 100 $\mu \mathrm{l}$ of methanol- $0.01 \% \mathrm{HCl}$, and separated on a $\mu$ BondPack analytical reverse-phase column $(3.9 \times 300 \mathrm{~mm})$ (Waters) according to Wilkinson et al. (1977). The column was eluted at $1.0 \mathrm{ml} \mathrm{min}{ }^{-1}$ with water-acetic acid-methanol (71:10:19) for $60 \mathrm{~min}$. Absorption at $530 \mathrm{~nm}$ was measured every second. A sample of each peak was freeze-dried and repurified by HPLC for analysis of IA, absorption of UV and visible light, and mass spectral analyses.

\section{Anthocyanin identification.}

The purity of anthocyanin fractions was verified by $\mathrm{A}_{\mathrm{UV} \max } / \mathrm{A}_{\mathrm{vis} \max }$ ratios less than 0.7 (Strack and Wray 1989). UV and visible spectra of anthocyanins in methanol-0.01\% 
$\mathrm{HCl}$ were measured in a Pharmacia LKB Ultraspec II. Highresolution fastatom bombardment was performed at the Midwest Center for Mass Spectrometry, University of Nebraska. HPLC co-chromatography of standard and derived anthocyanidins followed the HPLC procedure C. Delphinidin was purchased from Spectrum Chemical Manufacturing Corp. (Gardena, CA). Genistein and naringenin were obtained from ICN Biochemicals and Aldrich Chemical Company, respectively. Standard samples were recovered by acid derivation, ethyl acetate and amyl alcohol extraction, and HPLC procedure $\mathrm{C}$ of aubergine (delphinidin), strawberry (pelargonidin), raspberry (cyanidin), and Concord grape (malvidin) according to Harborne (1973).

\section{Anthocyanin quantitation.}

The abundance of the various anthocyanidin aglycones in exudate was estimated by HPLC with spectroscopically determined quantities (described below) of the aforementioned derived standards. The molar abundance of each anthocyanidin was calculated by comparing its integrated absorption peak to the integrated absorption peak of its corresponding anthocyanidin standard added at a molar abundance calculated from its accepted extinction coefficients.

\section{GC of anthocyanidins and sugars.}

The procedure for co-chromatography of anthocyanidins with derived standards was modified from the procedure of Bombardelli et al. (1977). Anthocyanidins were silylated in $200 \mu \mathrm{l}$ of Tri-Sil concentrate (Pierce) with $30 \mu \mathrm{l}$ of anhydrous dioxane and $15 \mu \mathrm{l}$ of tetrahydrofuran and heated to $60^{\circ} \mathrm{C}$ in a heating block for $30 \mathrm{~min}$. Reagents were evaporated with $\mathrm{N}_{2}$ from the cooled sample and redissolved in $100 \mu \mathrm{l}$ of hexane. A $10-\mu \mathrm{l}$ aliquot was injected into an SPB-1 glass column $(30 \mathrm{~m}$ $\times 0.75 \mathrm{~mm}$ ) with a $1.0-\mu \mathrm{m}$-thick film (Supelco) on a HP5890A chromatograph (Hewlett Packard). The column was heated at $1^{\circ} \mathrm{C} / \mathrm{min}$ from 280 to $310^{\circ} \mathrm{C}$. Injector and detector temperatures were set at $350^{\circ} \mathrm{C}$. The carrier gas (helium) flow was set at $12.5 \mathrm{ml} / \mathrm{min}$. TMS methyl glycosides were prepared from hydrolysates and analyzed on the SPB-1 column as previously described (York et al. 1985).

\section{TLC of anthocyanins and anthocyanidins.}

TLC of anthocyanidin aglycones (Nybom 1964) was developed with formic acid-hydrochloric acid-water (10:1:3) in the first dimension and with amyl alcohol-acetic acid-water (2:1:1) in the second dimension on Polygram CEL 400 TLC, 0.1-mm microcrystalline cellulose plates (Alltech). Anthocyanin glycosides were separated by means of the upper phase of $n$ butanol-acetic acid-water (4:1:5) (Harborne 1967) on K5 silica gel 150A TLC plates (Whatman). Relative amounts of separated anthocyanins were assessed by the optical density of individual colored bands of anthocyanins in the chromatogram, as determined by the Ambis Optical Imaging System using Ambis core software, version 4.20 (Ambis, San Diego, CA).

\section{Concentration assessment of individual anthocyanins for comparative determination of IA.}

Anthocyanin concentrations in assays were calculated spectrophotometrically. The molar extinction coefficients were adopted from Hungria et al. (1991a) except as noted otherwise, as follows (expressed as $\log _{10}$ of the extinction coefficients): delphinidin, 4.49 at $555 \mathrm{~nm}$ in ethanol-1\% $\mathrm{HCl}$; petunidin, 4.54 at $550 \mathrm{~nm}$ in the organic phase of $10 \%$ phosphoric acidphenol-toluene $(2: 2: 1)$; malvidin, 4.50 at $547 \mathrm{~nm}$ in methanol- $0.01 \% \mathrm{HCl}$; cyanidin, 4.48 at $538 \mathrm{~nm}$ in methanol-1\% $\mathrm{HCl}$ (Strack and Wray 1989); delphinidin 3-glucoside, 4.46 at $543 \mathrm{~nm}$ in methanol-1\% $\mathrm{HCl}$; petunidin 3-glucoside, 4.11 at $546 \mathrm{~nm}$ in methanol-0.1\% $\mathrm{HCl}$; and malvidin 3-glucoside, 4.45 at $520 \mathrm{~nm}$ in methanol- $0.01 \% \mathrm{HCl}$.

\section{ACKNOWLEDGMENTS}

We acknowledge the Midwest Center for Mass Spectrometry for fast atom bombardment spectrometry. This research was supported by Grant 92-37305-7877 of the CGRO of the U.S. Department of Agriculture. D.M.D. was supported by a Marquette University Fellowship.

\section{LITERATURE CITED}

Aguilar, J. M. M., Ashby, A. M., Richards A. J. H., Loake, G. J., Watson, M. D., and Shaw, C. H. 1988. Chemotaxis of Rhizobium leguminosarum biovar phaseoli towards flavonoid inducers of the symbiotic nodulation genes. J. Gen. Microbiol. 134:2741-2746.

Bombardelli, E., Bonati, A., Gabetta, B., Martinelli, E. M., and Mustich, G. 1977. Identification of anthocyanins by gas-liquid chromatography and mass spectrometry. J. Chromatogr. 139:111-120.

Dazzo, F. B., Truchet, G. L., Sherwood, J. E., Hrabak, E. M., and Gardiol, A. E. 1982. Alteration of the trifoliin A-binding capsule of Rhizobium trifolii 0403 by enzymes released from clover roots. Appl. Environ. Microbiol. 44:478-490.

Dickson, M. H., and Petzoldt, R. 1988. Deleterious effects of white seed due to $p$ gene in beans. J. Am. Soc. Hortic. Sci. 113:111-114.

Dunn, M. F., Pueppke, S. G., and Krishnan, H. B. 1992. The nod gene inducer genistein alters the composition and molecular mass distribution of extracellular polysaccharides produced by Rhizobium fredii USDA193. FEMS Microbiol. Lett. 97:107-112.

Harborne, J. B. 1967. Comparative Biochemistry of the Flavonoids. Academic Press, London.

Harborne, J. B. 1973. Phytochemical Methods: A Guide to Modern Techniques of Plant Analysis. Chapman and Hall, London.

Hartwig, U. A., Joseph, C. M., and Phillips, D. A. 1991. Flavonoids released naturally from alfalfa seeds enhance growth rate of Rhizobium meliloti. Plant Physiol. 95:797-803.

Heidstra, R., and Bisseling, T. 1996. Nod factor-induced host responses and mechanisms of Nod factor perception. New Phytol. 133:25-43.

Hungria, M., Joseph, C. M., and Phillips, D. A. 1991a. Anthocyanins and flavonols, major nod-gene inducers from seeds of a black-seeded common bean (Phaseolus vulgaris L.). Plant Physiol. 97:751-758.

Hungria, M., Joseph, C. M., and Phillips, D. A. 1991b. Rhizobium nod gene inducers exuded naturally from roots of common bean (Phaseolus vulgaris L.). Plant Physiol. 97:759-764.

Kape, R., Parniske, M., Brandt, S., and Werner, D. 1992. Isoliquiritigenin, a strong nod gene- and glyceollin-resistance inducing flavonoid from soybean root exudate. Appl. Environ. Microbiol. 58:1705-1710.

Mazza, G., and Miniati, E. 1993. Anthocyanins in Fruits, Vegetables, and Grains. CRC Press, Boca Raton, FL.

Noel, K. D. 1992. Rhizobial polysaccharides required in symbiosis with legumes. Pages 341-357 in: Molecular Signals in Plant-Microbe Communications. D. P. S. Verma, ed. CRC Press, Boca Raton, FL.

Noel, K. D., Duelli, D. M., Tao, H., and Brewin, N. J. 1996. Antigenic change in the lipopolysaccharide of Rhizobium etli CFN42 induced by exudates of Phaseolus vulgaris. Mol. Plant-Microbe Interact. 9:180186.

Noel, K. D., Sanchez, A., Fernandez, L., Leemans, J., and Cevallos, M. A. 1984. Rhizobium phaseoli symbiotic mutants with transposon Tn5 insertions. J. Bacteriol. 158:148-155.

Nybom, N. 1964. Thin-layer chromatographic analysis of anthocyanidins. Physiol. Plant. 17:157-164.

Peters, N. K., Frost, J. W., and Long, S. R. 1986. A plant flavone, luteolin, induces expression of Rhizobium meliloti nodulation genes. Science 233:977-980. 
Poupot, R., Martinez-Romero, E., Gautier, N., and Prome, J.-C. 1995. Wild type Rhizobium etli, a bean symbiont, produces acetyl-fucosylated, N-methylated, and carbamoylated nodulation factors. J. Biol. Chem. 270:6050-6055.

Reuhs, B. L., Kim, J. S., Badgett, A., and Carlson, R. W. 1994. Production of cell-associated polysaccharides of Rhizobium fredii USDA205 is modulated by apigenin and host root extract. Mol. Plant-Microbe Interact. 7:240-247.

Reuhs, B. L., Williams, M. N. H., Kim, J. S., Carlson, R. W., and Côté, F. 1995. Suppression of the Fix ${ }^{-}$phenotype of Rhizobium meliloti exoB mutant by LpsZ is correlated to a modified expression of the $\mathrm{K}$ polysaccharide J. Bacteriol. 177:4289-4296.

Schultze, M., and Kondorosi, A. 1996. The role of lipochitooligosaccharides in root nodule organogenesis and plant cell growth. Curr. Opin. Genet. Dev. 6:631-638.

Segovia, L., Young, J. P. W., and Martinez-Romero, E. 1993. Reclassification of American Rhizobium leguminosarum biovar phaseoli type I strains as Rhizobium etli sp. nov. Int. J. Syst. Bacteriol. 43:374-377.

Strack, D., and Wray, K. 1989. Anthocyanidins. Pages 325-356 in: Methods in Plant Biochemistry. Vol. 1, Plant Phenolics. J. B. Harborne, ed. Academic Press, San Diego, CA.
Tao, H., Brewin, N. J., and Noel, K. D. 1992. Rhizobium leguminosarum CFN42 lipopolysaccharide antigenic changes induced by environmental conditions. J. Bacteriol. 174:2222-2229.

van Rhijn, P., and Vanderleyden, J. 1995. The Rhizobium-plant symbiosis. Microbiol. Rev. 59:124-142.

VandenBosch, K. A., Noel, K. D., Kaneko, Y., and Newcomb, E. H. 1985. Nodule initiation elicited by noninfective mutants of Rhizobium phaseoli. J. Bacteriol. 162:950-959.

Wilkinson, M., Sweeny, J. G., and Iacobucci, G. A. 1977. High-pressure liquid chromatography of anthocyanidins. J. Chromatogr. 132:349-351.

Williams, M., Hrazdina, G., Wilkinson, M. M., Sweeny, J. G., and Iacobucci G. A. 1978. High-pressure liquid chromatographic separation of 3-glucosides, 3,5-diglucosides, and 3-(6-O-p-coumarylglucoside)-5glucosides of anthocyanidins. J. Chromatogr. 10:945-950.

York, W. S., Darvill, A. G., McNeil, M., Stevenson, T. T., and Albersheim, P. 1985. Isolation and characterization of plant cell walls and cell-wall components. Methods Enzymol. 118:3-40.

Yoshida, K., Sato, Y., Okuno, R., Kameda, K., Isobe, M., and Kondo, T. 1996. Structural analysis and measurement of anthocyanins from colored seed coats of Vigna, Phaseolus, and Glycine legumes. Biosci. Biotech. Biochem. 60:589-593. 